\title{
Results of Laboratory Monitoring in Patients Taking Isotretinoin for Acne
}

\author{
Mohammed Al-Haddab, MD, FRCPC; Alanoud Alhuqayl, MD; Heba Alsharif, MD; Dana Alolyet, MD; \\ Rawan Altaleb, MD
}

\section{PRACTICE POINTS}

- Isotretinoin is the mainstay treatment for severe acne.

- Cost and convenience to patients should always be considered.

- Frequent monitoring for laboratory changes during isotretinoin treatment is not warranted.

Isotretinoin is one of the most effective drugs for the treatment of all forms of acne vulgaris. It has been suspected of causing alterations in lipids and liver enzymes. The aim of this retrospective study was to determine the prevalence of laboratory changes among 371 patients with acne receiving isotretinoin therapy. Each patient's medical records were evaluated to determine baseline alanine aminotransferase (ALT), aspartate aminotransferase (AST), total cholesterol, and triglycerides (TGS) compared to levels recorded at 2 later readings following initiation of treatment with oral isotretinoin. Results indicated that isotretinoin can be administered with minimal concern regarding changes in serum transaminase and lipid profiles. Nevertheless, physicians should be cautious when administering isotretinoin in patients with a history of abnormal findings.

Cutis. 2021;108:43-45, E1-E2.

ntroduced in 1982, isotretinoin is a retinoid derivative that has been widely used to treat various dermatologic conditions such as acne vulgaris, rosacea, hidradenitis suppurativa, and hair folliculitis. ${ }^{1}$ It remains one of the most effective drugs for the treatment of all forms of acne vulgaris, especially the nodulocystic type, and exerts its effects via different mechanisms that affect the major domains involved in the pathogenesis of acne. ${ }^{2}$ One month after treatment initiation, isotretinoin suppresses sebum production by decreasing the size and activity of sebaceous glands. In addition, it notably stabilizes keratinization of the skin and decreases the number of Propionibacterium acnes, which will minimize the inflammation associated with acne. ${ }^{3,4}$ Despite its beneficial effects, isotretinoin therapy has been associated with several complications. The most commonly reported adverse effects include fissured lips, dry skin, eczema, epistaxis, dry eyes, gastrointestinal tract upset, angular stomatitis, and back pain. Less frequent systemic adverse effects have been reported and relate mainly to teratogenicity, pancreatitis, drug-induced hepatotoxicity, leukopenia, and thrombocytopenia. ${ }^{5}$

Isotretinoin use has been associated with alterations in hepatic and lipid profiles; elevations of serum liver enzymes and triglycerides (TGs) following isotretinoin treatment have been reported. ${ }^{4}$ Consequently, different protocols for laboratory monitoring during isotretinoin therapy have been established and utilized by various health care institutes. ${ }^{6}$ Despite the time and economic investment involved, certain protocols recommend repetition of liver function tests and several other laboratory parameters following a baseline test. ${ }^{7}$ The aim of this study was to determine the prevalence of laboratory changes in alanine aminotransferase (ALT), aspartate

From the Department of Dermatology, College of Medicine, King Saud University, Riyadh, Saudi Arabia.

The authors report no conflict of interest.

The eTables are available in the Appendix online at www.mdedge.com/dermatology.

Correspondence: Mohammed Al-Haddab, MD, FRCPC, PO Box 4545, Department of Dermatology, College of Medicine, King Saud University, Riyadh, 11472, Saudi Arabia (malhaddab@gmail.com).

doi:10.12788/cutis.0291 
aminotransferase (AST), cholesterol, and TGs among patients with acne receiving isotretinoin therapy, as well as to link the initial and second laboratory readings of the aforementioned parameters following initiation of isotretinoin treatment.

\section{Materials and Methods}

This retrospective cohort design study obtained patient data, including laboratory test results, from the Electronic System for Integrated Health Information at King Khalid University Hospital (KKUH)(Riyadh, Saudi Arabia). All patients older than 16 years who presented with acne vulgaris to the dermatology department at $\mathrm{KKUH}$; who received a course of isotretinoin for at least 4 weeks between 2011 and 2016; and who had available baseline readings of ALT, AST, cholesterol, and TGs, as well as 2 concurrent follow-up readings after isotretinoin treatment initiation, were included in this study. Patients with only 1 reading following treatment initiation and those receiving isotretinoin treatment for reasons other than acne were excluded. This study was approved by the institutional review board of the College of Medicine at King Saud University (Riyadh, Saudi Arabia)(E-18-3310).

Statistical Analysis-Data were entered into a Microsoft Excel document, and statistical analysis was performed using SPSS (version 22.0). Data were represented as numbers and percentages. Repeated measures analysis was performed using the Cochran $Q$ test to compare proportions of abnormal laboratory values among 3 groups: baseline, first reading, and second reading. When test results were significant, a post hoc test was used to compare proportions between any 2 groups. Moreover, a Spearman rank correlation was performed to investigate the association between the daily isotretinoin dose and the laboratory parameters. Results with $P<.05$ were considered statistically significant.

\section{Results}

During the study period, treatment with oral isotretinoin was undertaken by 386 patients at KKUH. Several of these patients were excluded due to incomplete medical records. The age of the studied patients ranged from 17 to 60 years, with a median age of 24 years (interquartile range, $20-28$ years). The daily administered dose ranged from 10 to $80 \mathrm{mg}$, with a median dose of $30 \mathrm{mg}$ (interquartile range, $20-40 \mathrm{mg}$ ), as illustrated in the Table. Repeated-measures analysis of liver enzymes (AST and ALT), total cholesterol, and TGs is detailed in eTable 1. Eight (2.2\%) of 371 patients showed abnormal baseline AST levels. The first follow-up measurements of AST revealed high levels in $7(1.9 \%)$ patients. This figure doubled (14 [3.8\%] patients) at the second follow-up, with no statistically significant differences $(P>.05)$. Likewise, ALT showed abnormally high levels at baseline and at both the first and second follow-ups (47/371 [12.7\%], 49/371 [13.2\%], and $37 / 371[10.0 \%]$, respectively) with no significant differences $(P>.05)$. Furthermore, the proportions

\section{Demographic Data of Acne Patients}

\begin{tabular}{ll}
\hline Demographic & Patient information \\
\hline Age, $y$ & \\
Range & $17-60$ \\
\hline Median & 24 \\
\hline IQR & $20-28$
\end{tabular}

Daily isotretinoin dose, $\mathrm{mg}$

\begin{tabular}{ll} 
Range & $10-80$ \\
\hline Median & 30 \\
\hline AbR & $20-40$ \\
\hline Abbreviation: IQR, interquartile range.
\end{tabular}

of high cholesterol levels at baseline and at both the first and second follow-ups (40/331 [12.1\%], 72/331 [21.8\%], and $62 / 331[18.7 \%]$, respectively) showed a statistically significant difference $(P=.001)$. The proportions of high cholesterol levels in both the first and second follow-ups were significantly higher than the baseline proportions $(P=.001$ and $P=.002$, respectively). However, the percentages of high cholesterol were reduced at the second reading relative to the first but with no significant differences. Regarding TGs, there was a statistically significant difference in the proportions of high levels over time (5/320 [1.6\%], 12/320 [3.8\%], and 14/320 [4.4\%] at baseline and at the first and second readings, respectively). Moreover, pairwise comparison among the 3 readings revealed a significant difference between the second follow-up and the baseline levels $(P=.048)$. eTable 2 demonstrates statistically significant positive weak associations between the daily administered isotretinoin dose and each of the cholesterol and TG levels, both at the first and second follow-up readings $(P<.05)$.

\section{Comment}

Evaluation of the effects of isotretinoin on liver enzymes and lipids has suggested that oral isotretinoin may cause alterations in liver aminotransferases (AST and ALT) and lipid profiles to various degrees. ${ }^{8}$ Furthermore, there are controversies regarding the routine laboratory monitoring of these patients. Some studies have reported severe alterations in serum liver transaminase and lipid levels, and they support the need for careful monitoring when treating patients with isotretinoin. However, other studies have reported that adverse effects are minimal, with no need for costly laboratory monitoring. ${ }^{9}$

Our study explored the profile of changes in liver aminotransferases (AST and ALT), cholesterol, and TGs in patients with acne who had been treated with oral isotretinoin. The cholesterol levels showed a nonprogressive 
increase, with a prevalence rate of $21.8 \%$ and $18.7 \%$ at the first and second follow-ups, respectively. Likewise, the frequency of high TG levels was $3.8 \%$ and $4.4 \%$, respectively, with significant differences from the baseline levels $(P=.041)$. However, liver enzymes were less affected by isotretinoin therapy than lipid profiles. Both AST and ALT showed nonsignificant minimal elevations during followup of the patients.

Similar to our findings, Zane et $\mathrm{al}^{6}$ at the University of California, San Francisco, studied 13,772 patients with acne who underwent oral isotretinoin therapy between 1995 and 2002. They reported a cumulative incidence of new abnormalities in patients with normal values at baseline at a frequency of $44 \%$ for TG levels, 31\% for total cholesterol levels, and $11 \%$ for transaminase levels. Moreover, they suggested that these abnormalities generally were transient and reversible. ${ }^{6}$ Another retrospective study in Brazil included 130 patients who were treated with isotretinoin for 3 months and reported that TG levels had increased beyond the normal range in $11 \%$ of patients, whereas $8.6 \%$ had elevated AST levels and $7.3 \%$ had elevated ALT levels. ${ }^{8}$ Comparable to our findings, Kizilyel et $\mathrm{al}^{10}$ concluded that isotretinoin appeared to have a greater effect on lipids than on liver enzymes, and they recommended its use with careful monitoring.

The transient effects of isotretinoin therapy on lipid profiles were highlighted in an earlier study. It has been reported that the changes in low-density lipoprotein and TGs returned to baseline levels 2 months following termination of treatment. ${ }^{11}$ Although many studies have reported alterations in serum transaminase and lipid levels, other studies fail to report any such effects. Alcalay et $\mathrm{al}^{7}$ investigated 907 patients who completed a treatment course lasting 5 to 9 months. They reported that only $1.5 \%$ of patients had serum TG levels above $400 \mathrm{mg}$. Additionally, serum levels of liver enzymes were not elevated to a degree necessitating discontinuation of treatment. They concluded that isotretinoin is a safe therapeutic drug and suggested that there is no need for routine laboratory follow-up in young healthy patients apart from a pregnancy test for females. ${ }^{7}$ In addition, Brito et $\mathrm{al}^{12}$ conducted a prospective clinical and laboratory evaluation of 150 patients being treated with oral isotretinoin prior to the start of therapy, 1 month after therapy initiation, and every 3 months thereafter until the completion of treatment. They found no statistically significant changes in liver transaminase, TG, or cholesterol levels. ${ }^{12}$ In another study of 30 participants, Baxter et $\mathrm{al}^{13}$ also reported no significant changes in TG or cholesterol levels measured at baseline or during treatment with isotretinoin. Furthermore, a systematic review and meta-analysis has estimated the laboratory changes that occur during isotretinoin therapy of acne vulgaris. ${ }^{14}$ The evidence revealed in this study does not support monthly laboratory testing for use of standard doses of oral isotretinoin for the typical patient with acne.

\section{Conclusion}

In our study, liver enzymes were less affected than lipids in patients who were treated with isotretinoin. Additionally, laboratory alterations in lipid profiles were nonprogressive and nonsevere. Consequently, isotretinoin may be administered with minimal concern for changes in serum transaminase and lipid profile. However, physicians should exercise caution when administering isotretinoin in patients with a history of abnormal findings.

\section{REFERENCES}

1. Kaymak $Y$, Ilter N. The results and side effects of systemic isotretinoin treatment in 100 patients with acne vulgaris. Dermatol Nurs. 2006;18:576-580.

2. Al-Mutairi N, Manchanda $Y$, Nour-Eldin O, et al. Isotretinoin in acne vulgaris: a prospective analysis of 160 cases from Kuwait. J Drugs Dermatol. 2005;4;369-373.

3. Agarwal US, Besarwal RK, Bhola K. Oral isotretinoin in different dose regimens for acne vulgaris: a randomized comparative trial. Indian J Dermatol Venereol Leprol. 2011;77:688-694.

4. Hansen TJ, Lucking S, Miller JJ, et al. Standardized laboratory monitoring with use of isotretinoin in acne. J Am Acad Dermatol. 2016;75:323-328

5. Strauss JS, Rapini RP, Shalita AR, et al. Isotretinoin therapy for acne: results of a multicenter dose-response study. J Am Acad Dermatol. 1984;10:490-496.

6. Zane LT, Leyden WA, Marqueling AL, et al. A population-based analysis of laboratory abnormalities during isotretinoin therapy for acne vulgaris. Arch Dermatol. 2006;142:1016-1022.

7. Alcalay J, Landau M, Zucker A. Analysis of laboratory data in acne patients treated with isotretinoin: is there really a need to perform routine laboratory tests? J Dermatolog Treat. 2001;12:9-12.

8. Vieira AS, Beijamini V, Melchiors AC. The effect of isotretinoin on triglycerides and liver aminotransferases. An Bras Dermatol. 2012; 87:382-387.

9. Bauer LB, Ornelas JN, Elston DM, et al. Isotretinoin: controversies, facts, and recommendations. Expert Rev Clin Pharmacol. 2016;9:1435-1442.

10. Kizilyel O, Metin MS, Elmas ÖF, et al. Effects of oral isotretinoin on lipids and liver enzymes in acne patients. Cutis. 2014;94:234-238.

11. Bershad S, Rubinstein A, Paterniti JR, et al. Changes in plasma lipids and lipoproteins during isotretinoin therapy for acne. $N$ Engl J Med. 1985;313:981-985.

12. Brito MDFDM, Sant'Anna IP, Galindo JCS, et al. Evaluation of clinical adverse effects and laboratory alterations in patients with acne vulgaris treated with oral isotretinoin. An Bras Dermatol. 2010;85:331-337.

13. Baxter KF, Ling TC, Barth JH, et al. Retrospective survey of serum lipids in patients receiving more than three courses of isotretinoin. J Dermatolog Treat. 2004;14:216-218.

14. Lee YH, Scharnitz TP, Muscat J, et al. Laboratory monitoring during isotretinoin therapy for acne: a systematic review and meta-analysis. JAMA Dermatol. 2016;152:35-44. 


\section{APPENDIX}

\section{eTABLE 1. Effects of Oral Isotretinoin Administration on Repeated Measures of Liver Enzymes, Total Cholesterol, and Triglycerides}

\begin{tabular}{|c|c|c|c|c|c|}
\hline \multirow[b]{2}{*}{ Laboratory variable } & \multirow[b]{2}{*}{ Baseline reading, $\mathrm{n}(\%)$} & \multirow[b]{2}{*}{ First reading, $\mathrm{n}(\%)$} & \multirow[b]{2}{*}{ Second reading, $\mathrm{n}(\%)$} & \multicolumn{2}{|c|}{ Cochran $Q$ test } \\
\hline & & & & Test statistic & $P$ value \\
\hline \multicolumn{6}{|l|}{$\begin{array}{l}\text { AST } \\
(n=371)\end{array}$} \\
\hline $\begin{array}{l}\text { Normal } \\
(\leq 40 \mathrm{U} / \mathrm{L})\end{array}$ & $363(97.8)$ & $364(98.1)$ & $357(96.2)$ & 3.739 & .154 \\
\hline $\begin{array}{l}\text { High } \\
(>40 \mathrm{U} / L)\end{array}$ & $8(2.2)$ & $7(1.9)$ & $14(3.8)$ & & \\
\hline \multicolumn{6}{|l|}{$\begin{array}{l}\text { ALT } \\
(n=371)\end{array}$} \\
\hline $\begin{array}{l}\text { Normal } \\
(\leq 40 \mathrm{U} / \mathrm{L})\end{array}$ & $324(87.3)$ & $322(86.8)$ & $334(90.0)$ & 3.263 & .196 \\
\hline $\begin{array}{l}\text { High } \\
(>40 \text { U/L) }\end{array}$ & $47(12.7)$ & 49 (13.2) & $37(10.0)$ & & \\
\hline \multicolumn{6}{|l|}{$\begin{array}{l}\text { Cholesterol } \\
(n=331)\end{array}$} \\
\hline $\begin{array}{l}\text { Normal } \\
(\leq 5.20 \mathrm{mmol} / \mathrm{L})\end{array}$ & $291(87.9)$ & $259(78.2)$ & 269 (81.3) & 14.889 & $.001^{\mathrm{a}}$ \\
\hline $\begin{array}{l}\text { High } \\
(>5.20 \mathrm{mmol} / \mathrm{L})\end{array}$ & $40(12.1)$ & & $62(18.7)$ & & \\
\hline \multicolumn{6}{|l|}{$\begin{array}{l}\text { Triglycerides } \\
(n=320)\end{array}$} \\
\hline $\begin{array}{l}\text { Normal } \\
(<2.30 \mathrm{mmol} / \mathrm{L})\end{array}$ & $315(98.4$ & 308 (96.3) & $306(95.6)$ & 6.381 & $.041^{\mathrm{b}}$ \\
\hline $\begin{array}{l}\text { High } \\
(\geq 2.30 \mathrm{mmol} / \mathrm{L})\end{array}$ & & $12(3.8)$ & $14(4.4)$ & & \\
\hline $\begin{array}{l}\text { Abbreviations: AST, asp } \\
\text { apairwise comparison re } \\
(P=.002) \text {. }\end{array}$ & $\begin{array}{l}\text { te aminotransferase; ALT, ala } \\
\text { led significant differences be }\end{array}$ & $\begin{array}{l}\text { e aminotransferase. } \\
\text { een reading } 1 \text { vs baselin }\end{array}$ & reading $(P=.001)$ and readi & ling 2 vs baseline & eading \\
\hline
\end{tabular}


eTABLE 2. Correlation Between Daily Isotretinoin Dose and Laboratory Investigations at Different Time Periods

\begin{tabular}{lll}
\hline $\begin{array}{ll}\text { Laboratory value } \\
\text { (follow-up reading) }\end{array}$ & Daily isotretinoin dose \\
\hline AST (first reading) & Pearson $r$ & -0.011 \\
\hline AST (second reading) & P value & .828 \\
\hline ALT (first reading) & Pearson $r$ & -0.011 \\
\hline ALT (second reading) & P value & .828 \\
\hline Cholesterol (first reading) & Pearson $r$ & 0.078 \\
\hline TGs (first reading) & P value & .130 \\
\hline Cholesterol (second reading) & Pearson $r$ & 0.099 \\
\hline & $P$ value & .053 \\
\hline & $P$ value & $<.001^{\mathrm{a}}$ \\
\hline & $P$ value & $.007^{\mathrm{a}}$ \\
\hline & Pearson $r$ & 0.144 \\
\hline & $P$ value & $.011^{\mathrm{a}}$ \\
\hline & Pearson $r$ & 0.159 \\
\hline & $P$ value & $.005^{\mathrm{a}}$ \\
\hline
\end{tabular}

Abbreviations: AST, aspartate aminotransferase; ALT, alanine aminotransferase; TG, triglyceride. ap $<.05$. 